\title{
Estratificação, sociabilidades, táticas e estratégias na produção de espaços no "Maior São João do Mundo"
}

Resumo: Este artigo objetiva compreender as configurações espaciais efetivadas pelas sociabilidades entre os agentes sociais nos espaços do Parque do Povo na festa de São João de Campina Grande - PB. Observamos a produção de espaços/lugares em meio à lógica imposta pelos gerentes culturais e as ressignificações efetuadas pelos agentes. As configurações se deram em um espaço pensado sob a égide das distinções sociais por meio da variação de preços e do monopólio de produtos a serem consumidos. Os mesmos produtos sofreram oscilações de preços e de prestígio/valor social quando referidos aos espaços/lugares nos quais eram consumidos. Através da observação participante apreciamos as interações na conformação de lugares com significados comumente compartilhados na delimitação dos espaços de sociabilidade. Concluímos que através da ressemantização e ressignificação os agentes sociais reordenaram os espaços implicando em lugares por eles referenciados em compartilhamentos intra e extragrupais.

Palavras-chave: sociabilidades, estratégias, táticas, espacialidades, ressignificação.

\section{Stratification, sociability, tactics and strategies in the production of spaces in "Maior São João do Mundo"}

\begin{abstract}
The aim of this article is to comprehend spatial configuration effected by sociability between social agents at "São João" a traditional party located at "Parque do Povo" in Campina Grande, PB. It was observed the production of spaces/places along with the logic imposed by cultural managers and the significations made by cultural agents. The local of the configurations occurred in a space thought under the aegis of social distinctions through changes in prices and the monopoly of products to be consumed. These products have experienced price oscillations, prestige and social value concerning places and spaces in which they were consumed. Through participative observation it was appreciated the interactions shaping places with meanings commonly shared in the delimitation of social spaces. To conclude it was observed that through resemantization and ressignification, the social agents' reordered places implicating in spaces referenced by them as a local to share inter and extra group interactions.
\end{abstract}

Key-words: sociability, strategies, tactics, spatiality, ressignification.

Artigo recebido em 07/12/2014 e aprovado em 03/06/2015. 


\section{TIAGO FERNANDES ALVES}

\section{O PARQUE DO POVO E O ESPAÇO DA POLÍTICA}

Este artigo é fruto de observações efetuadas no Parque do Povo na cidade de Campina Grande - PB no ano de 2013 durante os festejos juninos que acontecem todos os anos no mês de Junho. Festa característica da região é tida como o "Maior São João do Mundo" com sua duração de aproximadamente trinta dias.

A estratificação do espaço do Parque do Povo foi pensada pela lógica dos ajustamentos econômicos empresariais, constituintes das práticas do fazer político da cidade de Campina Grande - PB. Os espaços foram preenchidos sob a ótica da parceria público-privada conferindo ordenações previamente arquitetadas. É comum nos últimos anos o envolvimento dos poderes públicos com os setores da iniciativa privada na forma como a festa de São João em Campina Grande é pensada. Ao passo que institucionalizou-se, a festa passou a ser alvo do crescente interesse tanto político quanto empresarial, levando a acirradas disputas entre correligionários dos poderes instituídos e seus opositores.

A década de 1990 é particular para o evento que passa por um processo de reformulação diante das propostas de resgate das tradições juninas ${ }^{\text {II }}$. Os movimentos dos setores políticos se engajaram na tentativa de recriar um passado que estava se perdendo, um retorno aos antigos festejos em respeito às tradições e à cultura locais no culminar de um "ethos" junino. Cria-se, portanto, uma série de imagens "que reproduza todo um imaginário da tradição da festa de São João"III . O espaço do Parque do Povo é então repensado, sua estrutura se firma para uma vazão cada vez maior de pessoas. Ornamentos e novos serviços são postos no intuito da afirmação do evento como o "Maior São João do Mundo".

Apesar de ser um espaço público o Parque abriga interesses dos mais variados setores privados, sendo constantemente cercado (fechado ao público em geral) e estruturado estrategicamente aos ímpetos público-privados, onde os poderes estatais em conjunção com as iniciativas privadas reelaboram o espaço de forma singular.

Desde 1983 o Parque do Povo é o palco principal dos festejos juninos. Seu espaço é elaborado de maneiras distintas de acordo com as mudanças políticas em busca de uma "nova gestão" no modo de realização do evento, ou no ensejo de adequação do espaço de acordo com as novas demandas emergentes com o passar dos anos.

Antes da nova disposição espacial, a do ano de 2013 aqui observada, o palco principal ficava na parte inferior do Parque, juntamente com algumas barracas e quiosques espalhados pela parte mediana da festa. As barracas mais abastadas ficavam na parte superior, destinada aos que se dispõe a gastar mais. A parte central, onde se encontra a pirâmide, única parte coberta do Parque, continuou recebendo as disputas entre as quadrilhas juninas representantes de bairros da cidade e bandas de menor porte em sua área interna durante a noite. Aos sábados pela manhã a pirâmide recebe também o Momento Junino, evento realizado em conjunto com políticos e empresários televisionado por uma emissora local.

\section{A CONSTRUÇÃO DO OLHAR SOBRE O EVENTO JUNINO}

Objetivando compreender os processos de ressignificação/ressemantização dos espaços estrategicamente dispostos, fizemos uso de observação participante que possibilitou a compreensão da estratificação sócio-espacial empreendida na festa com suas subdivisões econômicas, e o modo como os agentes sociais elaboraram novas configurações espaciais em processos de sociabilidade. 


\section{TIAGO FERNANDES ALVES}

Empreendemos, portanto, analisar e entender como os grupos e agentes sociais diante das configurações impostas pelas vias institucionais estratégicas, taticamente reapropriaram-se dos espaços, reelaborando-os em constante fluxo de produção simbólico-representacional. Desse modo buscamos entender a relação dialética entre os espaços de representação e as representações do espaço ${ }^{\mathrm{IV}}$, modo pelo qual analisamos a produção do espaço na reconfiguração de suas pré-disposições estratégicas por vias táticas de reapropriação/reelaboração dos espaços.

O tempo é aqui tomado como diacrônico/sincrônico, uma vez que nos preocupamos em princípio com o processo de produção do espaço, o momento de sua produção, ressignificação que se dá no tempo presente, ou seja, as representações do espaço. Contudo, para que haja representações em caráter sincrônico é necessário reportar-se ao pretérito espacial, ou seja, às representações do espaço há muito configuradas, estacionadas sob a forma de imperativos institucionais, categorias e estratificações pré-projetadas, seu caráter diacrônico.

Através de Michael de Certeau ${ }^{\mathrm{V}}$ percebemos as ordenações e estratificações espaciais como estratégias que se interpõem enquanto mecanismos gerenciais do espaço do Parque do Povo descontextualizando o "outro", ou seja, os agentes sociais enquanto produtores de lugares. Desta forma, os espaços previamente arquitetados pelos interesses estratificantes foram reordenados pelos agentes sociais enquanto táticas de rearranjos das espacialidades através da produção de sentidos.

Trava-se, portanto, um embate entre os produtores de espacialidades. De um lado os agenciadores culturais no sentido trazido por Bauman ${ }^{\mathrm{VI}}$, gerentes que utilizam/instrumentalizam as produções culturais em forma de rendimentos condizentes à lógica do mercado, e no outro os agentes sociais em processos de sociabilidades, estabelecendo táticas de reapropriação das espacialidades na conformação de sentidos coletivamente compartilhados em novas formas de sociação.

Partindo de Simmel ${ }^{\mathrm{VII}}$ entendemos as novas ordenações que emanam dos agentes em relações recíprocas, contudo, nem sempre harmônicas, os quais criam e recriam novas formas de sociação a partir de suas disposições conteudísticas. As disposições conteudísticas podem ser vistas sob a ótica do compartilhamento entre os agentes de um mínimo ético intergrupal. Os espaços são assim preenchidos em busca de uma coalizão de conteúdos diversos em formas de sociação grupais. Os grupos sociais interagem construindo e refazendo as fronteiras entre si. Mas essas interações não devem ser tomadas como compartilhamento de espaços de forma harmônica. As disputas e embates espaciais entre os grupos LGBT's, os "alternativos", os frequentadores da parte superior e da parte inferior, as disputas territoriais em frente ao palco etc. foram entendidos tomando como constitutivo os vários conflitos que permearam as negociações entre eles.

Ainda segundo Simmel a sociação deve ser vista como processos que ora se harmonizam, ora se desfazem, sendo um constante fluxo de novas formas de sociabilidade sob conteúdos também díspares ${ }^{\text {VIII }}$. Os lugares produzidos pelos agentes sociais aparecem como espaços de compartilhamento de similitudes conteudísticas que apaziguam e conferem relativa harmonia dentro dos grupos.

De acordo com Heitor Frúgoli Jr. ${ }^{\text {IX }}$ a produção de espacialidades urbanas refere-se a uma organização moral e física onde os indivíduos constituem territorialidades, circunscrevendo espacialidades em busca do estabelecimento de relações situadas em um lugar portador de significado e sentido ${ }^{\mathrm{C}}$. Para tal empreendimento os indivíduos, através da noção de conversação trazida por Simmel, elaborariam significados e sentidos mutuamente compartilhados por meio de trocas de 


\section{TIAGO FERNANDES ALVES}

palavras/discursos/enunciações que estabeleceriam regras de conduta dentro dos grupos, não permitindo a exacerbação das individualidades ${ }^{\mathrm{XI}}$. Nestes termos, os agentes agem na consolidação de relativa harmonia dentro dos grupos nos quais transitam. Contudo, rupturas, desacordos e passagens intragrupais são constantes sendo, portanto, forçados a todo instante a reelaborar suas relações entre si.

Pensando os grupos não como entidades fechadas possuidores de regras rígidas, espacialidades definidas e fronteiras hermeticamente delimitadas, em consonância com Fredrik Barth ${ }^{\mathrm{XII}}$ observamos que as espacialidades são reconfiguradas em todo momento pelos agentes situados em vários grupos ao mesmo tempo. Não há, portanto, fronteiras que repliquem a inércia aos agentes, uma vez que no espaço do Parque do Povo uma multiplicidade de grupos, pessoas e situações ocorrem simultaneamente, seria empobrecedor visualizá-los enquanto sistemas ou padrões encerrados em si mesmos.

Neste sentido, atentamos para o fato de que os espaços e lugares elaborados pelos grupos e agentes não constituem condutas pré-estruturadas na forma de disposições coercitivas. Somos condizentes com a proposta de Bernard Lahire ${ }^{\mathrm{XIII}}$ no que concerne a apropriação dos agentes das disposições como gerenciadoras das condutas sociais não apenas de forma impositiva, mas como constituídas por processos de apropriação e reapropriação dos habitus, ora afirmando-os, ora ocultando-os em complexos movimentos de ajustes de condutas de acordo com os campos pelos agentes transitados. O habitus como sistema de disposições que orientariam as condutas individuais na conformação dos campos ${ }^{\mathrm{XIV}}$ aparece, nesta perspectiva, como modelo que não apenas padronizaria os processos de sociabilidade sob as insígnias de formas pré-estruturadas, mas que podem sofrer alterações de acordo com as experiências vividas pelos agentes no presente, transitando em diversos campos sem que para isso necessitem participar efetivamente de seus embates constitutivos ${ }^{\mathrm{XV}}$.

As representações simbólicas dos espaços não conferem seu fechamento mas a possibilidade de provar várias sensações ao mesmo tempo, transitar em um mar de sentidos, intercambiando símbolos culturais e representações variadas ${ }^{\mathrm{XVI}}$, rearranjando as espacialidades na conformação de lugares significativos em disposições criadas e recriadas a todo instante.

\section{ASPECTOS METODOLÓGICOS}

Com fins de atingir os objetivos aqui propostos fizemos uso da observação participante e participação observante ${ }^{\mathrm{XVII}}$, com o auxílio de um diário de campo, possibilitando a compreensão da estratificação sócio/espacial empreendida na festa com suas subdivisões econômicas, e o modo como os agentes sociais (re)elaboraram novas configurações espaciais em processos de sociabilidade.

Cartazes e cardápios foram analisados em busca dos sentidos atribuídos pelos vendedores e comerciantes aos seus produtos. Neste sentido os nomes por eles dados aos mesmos produtos serviram de base para entender os processos de ressemantização propiciada pelos agentes sociais de acordo com as espacialidades/lugares nos quais estes bens e serviços eram consumidos.

As observações foram estabelecidas de acordo com o critério de saturação de $\operatorname{dados}^{\mathrm{XVIII}}$, não sendo previamente constituída a quantidade de visitas ao campo. Ao perceber que as informações obtidas não mais contribuiriam para a compreensão do objeto no tocante aos objetivos aqui propostos as observações foram encerradas. 


\section{TIAGO FERNANDES ALVES}

Não foram realizadas entrevistas de modo estruturado, apenas algumas interlocuções com alguns agentes de modo a firmar um mero diálogo. As abordagens não seguiram nenhum critério em especial. Elas foram promovidas como ferramenta de comunicação básica entre os agentes (observador, agentes e grupos) no intuito de promover o que Simmel ${ }^{\mathrm{XIX}}$ chama de "mínimo ético" no processo de sociabilidade, permitindo ao observador o trânsito entre os grupos e o acesso aos agentes sociais. A ideia foi estabelecer através do que o mesmo autor denomina de conversação ${ }^{\mathrm{XX}}$ dandonos a possibilidade de, não apenas observar, mas também participar do evento em suas variadas e complexas lógicas semânticas e simbólicas.

Objetivando compreender os processos de ressignificação/ressemantização dos espaços/lugares promovidos pelos grupos e agentes sociais, entendemos que a delimitação dos fatos a serem observados não seria condizente ao mérito da pesquisa. $\mathrm{O}$ lócus da pesquisa foi o processo de produção das espacialidades, o momento em que são produzidos espaços/lugares pelos agentes em sociabilidades, reconfigurando seja de forma física, seja de forma interlocutória, recriando espaços através de discursos, dando fluidez, redistribuindo perlocutoriamente as relações de poder e redimensionando as estratificações sociais. Para tanto devemos pensar a atuação do observador em meio ao acontecimento de seu objeto a ser pesquisado, sua emergência no momento de sua produção. Neste sentido, a pesquisa ensejou desvendar os códigos criados e produzidos com o espaço em busca de sua gênese, intervenção e definhamento ${ }^{\mathrm{XI}}$. Entender o processo de produção do espaço é buscar os mecanismos que o engendram, o mantém e o transformam que, neste caso, seriam as representações do espaço e os espaços de representação ${ }^{\mathrm{XXII}}$ no que concerne a relação dialética entre o percebido, o concebido e o vivido. Existe, portanto, uma relação conflituosa entre as forças de onde emanam as representações do espaço como sendo o espaço concebido, das estratégias urbanistas, políticas e instituições, e o espaço de representação, espaço dos habitantes, dos usuários, o percebido e o vivido enquanto táticas de reapropriação do espaço.

$\mathrm{O}$ espaço deve ser visto como produção ${ }^{\mathrm{XXIII}}$, como processualidade que implica disputas ideológicas, o lugar do saber materializado nos confrontos discursivos. Assim, o espaço é um devir, um presente sempre pretérito, um acontecer em constante fuga, substancializado nas práticas e fazeres humanos em relações recíprocas objetivas ou não.

O espaço das enunciações pressupõe um auditório social no qual a palavra dirige-se a um interlocutor enquanto "expressão que organiza a atividade mental"

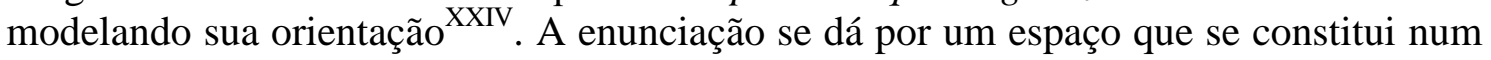
movimento dialético entre a reflexão de cada indivíduo e o horizonte social no qual ele tanto organiza suas reflexões internas quanto elabora sua fala de acordo com os dispositivos ideológicos do grupo o qual pertence ou o qual se dirige ${ }^{\mathrm{XXV}}$. O espaço se constrói perlocutoriamente de acordo com a relação dialógica entre o entendimento do ator acerca das formas instituídas sobre o uso dos espaços e a forma como ele se apropria destes signos dando-lhes novas perspectivas. O horizonte social pensado por Bakhtin em muito se assemelha ao espaço de representação proposto por Lefebvre quando pressupõe espaços discursivamente construídos a partir das relações socialmente estabelecidas em um lugar simbólico, inseridas em um espaço geográfico e imersas em uma temporalidade que configuram os sentidos e as lógicas das enunciações.

\section{O CHURRASQUINHO, O ESPETO, A CACHAÇA E OS PROCESSOS DE RESSEMANTIZAÇÃO}




\section{TIAGO FERNANDES ALVES}

Em busca das diferenciações estratégicas e dos mecanismos de distinção em torno das produções dos espaços e lugares, tomamos alguns termos como modos elaborados pelos agentes na consolidação das diferenciações sociais dentro do Parque do Povo.

Tendo em vista o monopólio consequência dos acordos entre marcas, empresas e produtos e a prefeitura da cidade, procuramos entender as diferenciações sociais a partir das adjetivações usadas pelos agentes para desqualificar e valorizar os usos e consumos dos mesmos produtos, bens e serviços.

As observações participantes e a análise de cartazes e cardápios dos estabelecimentos e barracas, no que concerne aos usos, consumos e freqüentações dos espaços da festa permitiram visualizar os atos de fala enquanto mecanismos constitutivos de estratégias das relações de poder. Os termos cunhados para designar os mesmos produtos e serviços serviram como instrumentos de distinção social concernente às suas formas e lugares de utilização e consumo. Assim, a mesma comida ou a mesma bebida puderam ser consumidas por grupos distintos em lugares distintos sofrendo uma série de designações pejorativas ou valorativas de acordo com as referidas espacialidades.

Os organizadores da festa este ano, estrategicamente, puseram um palco secundário na parte inferior do Parque do Povo, parte esta destinada aos frequientadores que possuem maior capital econômico. Tal estratificação é visível na medida em que se puderam pagar extensas quantias em dinheiro por um petisco que em barracas menos elaboradas, ou mesmo nos pequenos quiosques espalhados pela área central se gastaria muito menos.

O mesmo "churrasquinho" em uma barraca localizada na parte inferior da festa, que recebe o nome de "espeto", custando seis reais, pôde ser consumido com a designação de "churrasquinho de gato", ou "chugatinho" pela terça parte do preço em um quiosque na parte central. Pudemos perceber que o mesmo alimento recebeu uma designação pejorativa para distingui-lo, segregá-lo do consumo realizado na parte inferior, central ou superior. A distinção se efetiva através do violento discurso que deslegitima $^{X X V I}$ tanto o consumidor quanto o vendedor como consumidores de produtos de qualidade inferior, sendo eles mesmos, portanto, inferiores, pertencentes a classes indistintas, o povo. Esta visão se tornou factível no momento em que as mesmas pessoas que consumiam o "chugatinho", quando o fizeram em uma barraca na parte inferior, chamaram o garçom e pediram um "espeto" ou "espetinho". O mesmo produto passou por uma valorização apenas por seu deslocamento espacial, sendo resignificado agregando-lhe valor social, pois não deixou de ser carne, mas deixou de ser carne de "gato" para se tornar carne bovina. Os cardápios também seguiram essa conduta dando nomes mais elaborados aos mesmos produtos vendidos em qualquer parte da festa em busca de um serviço diferenciado.

Alguns cardápios, na parte inferior e, portanto, nas barracas abastadas, se encontravam na porta do estabelecimento. Tal estratégia foi em realidade tanto uma proposição por parte dos órgãos competentes quanto uma jogada de marketing para atrair o público. Ficou claro que à medida que nos dirigíamos ao "sul" da festa os preços iam ao sentido "norte", ou seja, ficava mais caro a cada metro percorrido. No caso dos quiosques os preços e nomes dos produtos ali comercializados se encontravam pendurados, em sua maioria, na parte de dentro do estabelecimento, dando maior visibilidade mas também agilizando o atendimento. Tanto nos quiosques quanto nas barracas menos elaboradas foi comum o uso de nomenclaturas com conotações 


\section{TIAGO FERNANDES ALVES}

religiosas às bebidas como "capeta", ou sexuais como "pau do índio" que são batidas geralmente elaboradas pelos próprios comerciantes.

A diferenciação ou o sentimento de distinção se dá pelo nome e localização do lugar, seu status enquanto marca reconhecida nos bastidores do fazer político e empresarial da cidade. Em A Distinção, Bourdieu mostra como os mecanismos de hierarquização e diferenciação dos gostos exprimem a necessidade de distinção entre a as classes abastadas e as classes populares. Os gostos culturais são violentos processos de distinção através da introjeção de habitus respectivos aos campos, classes e segmentos sociais aos quais pertencem e transitam os agentes ${ }^{\text {XVIII }}$. Aquilo que aparece enquanto mecanismo de distinção e violência simbólica na realidade francesa se torna, no Parque do Povo, uma violência da distinção por meio da posse material, mais contundente e visível. A distinção social não opera por modelos e categorizações dos gostos ou da virtude naturalizada, mas como posse de bens, na capacidade de consumo. Ao consumir a mesma bebida que qualquer outro frequentador da festa resta à classe abastada distinguir-se pagando a mais por um petisco ou por uma bebida, atribuindo-lhe outros nomes, ressignificando seu valor social. A prática discursiva é o que distingue o "aperitivo" da "cana" e da "cachaça", o "espeto" do "churrasquinho", o "beber" do "tomar".

Os donos de barracas mais abastadas são empresários que possuem contato íntimo com as gestões que se revezam no poder político. Ora uns são mais beneficiados por tal gestão, ora outros grupos assumem os melhores e privilegiados lugares. A dança de interesses este ano aponta para o culminar de um processo que há algum tempo vem se consolidando. A privatização de certos setores do consumo e do entretenimento. Este ano houve a significativa modificação em relação aos camarotes, antes acessíveis apenas por meio de convites, tendo este ano seu acesso por meio de entradas pagas. As barracas que se encontravam na parte de baixo dos camarotes pagaram taxas de aluguel que ultrapassaram os três mil reais em contraste com as barracas vinculadas a prefeitura que pagaram em torno de setecentos e cinquenta reais no setor superior perto do palco. À classe abastada resta a compra de um camarote, uma área vip, isolada do povo e da multidão como recurso distintivo. O espaço público e comunitário da festa é segregado por uma lógica privativa que o ocupa em privilégio dos que podem pagar para acessá-lo.

Ao caminhar pelas ruas do Parque do Povo pudemos encontrar uma variação de preços que chegaram a mais de $35 \%$ entre as barracas da parte inferior e a mais de $55 \%$ entre estas e as barracas da parte superior. Esta variação seguiu a risca o sentido geográfico da festa. Quanto mais se descia mais caro ficavam as comidas e bebidas. O mesmo prato pôde variar $35 \%$ entre as barracas da parte inferior sendo a variação ainda maior em relação às barracas do setor superior. Algumas bebidas poderiam custar $\mathrm{R} \$ 3,50$ na parte superior e $\mathrm{R} \$ 4,50$ na parte inferior, fora os $10 \%$ destinada à taxa de serviço que não chega a ser obrigatória, totalizando assim $\mathrm{R} \$ 4,95$, uma variação de mais de $41 \%$. Outra bebida obteve uma variação de $100 \%$ ao ter seu valor dobrado em algumas barracas, de $\mathrm{R} \$ 3,00$ à $\mathrm{R} \$ 6,00$.

Apesar de um acordo estabelecido entre os fabricantes de bebidas e os donos das barracas, tanto na parte inferior quanto na superior, não houve seu cumprimento sendo o preço entregue à lógica do mercado da distinção e do lucro. Observamos que apesar de algumas barracas cobrarem mais caro eram as que estavam mais cheias, pois representam as marcas já consolidadas, restaurantes e bares que possuem certa tradição na cidade. Símbolos de distinção social essas barracas oferecem lugares privilegiados aos mais aptos economicamente, aqueles que podem ser distinguidos pelo poder de consumo. Deste modo, aqueles que se encontram na parte superior desistem de descer a 


\section{TIAGO FERNANDES ALVES}

parte inferior por se tratar de um gasto significativamente elevado. Os que embaixo se encontravam não necessitaram subir, pois possuíam um palco e shows ao seu alcance uma vez que uma pequena estrutura foi montada para apresentações de bandas e shows. Telões também foram montados para que os jogos de futebol pudessem ser transmitidos.

Ao término de algumas apresentações na parte superior pudemos presenciar o movimento das pessoas que desciam em grupos em busca das saídas do Parque do Povo na parte inferior. Duas das sete entradas se situaram na parte inferior, sendo grande o movimento de pessoas que transitavam pelas vielas entre as barracas. Elas passavam olhando as pessoas de dentro das barracas que foram, em algumas situações, tratados com piadinhas e pilhérias, como lugar de "playboy" ou "boyzinho". Lugar de "gente besta" que gasta muito mais para beber e comer as mesmas coisas que eles comem e bebem na parte de cima.

Contudo, o olhar era recíproco. Elas passavam sob o olhar dos que estavam dentro das barracas que as observavam com certo receio e até temor, pois se trata do povo, dos que frequentam o "forró da facada", que ficam no "pé do palco", comem "churrasquinho" e "tomam cana". Nas barracas não se "toma cana", "bebe-se" um aperitivo ou cachaça. O verbo "tomar" ganha uma conotação mais selvagem, bárbara, plebeia, rude e grosseira em relação ao verbo "beber". Expressa a luta aberta, mas sigilosa pelo poder da distinção das limitações entre aqueles que, mesmo consumindo os mesmos produtos assumem os papeis de superioridade e inferioridade agindo pela ressignificação de seus atos. Contudo, o processo de distinção engloba ambos os grupos. Ao referirem-se aos "playboys" como "gente besta" eles tentam estabelecer uma distinção com os demais que não participam de seu entorno. Constrói-se um sentimento de receio entre os grupos. Em seu trabalho sobre os bois bumbás da cidade de Campina Grande, Tiago Fernandes Alves relata os embates entre as manifestações culturais da periferia e os grandes investimentos destinados aos eventos das classes abastadas da referida cidade ${ }^{\mathrm{XXVIII}}$ no que concerne o Carnaval dos que Ficam e o Encontro da Nova Consciência e da Consciência Cristã. As disputas passam todo o tempo entre a luta pela legitimação de suas manifestações por parte dos brincantes de bois e as classes abastadas e demais setores que de certa maneira não os reconhecem como portadores culturais. Assim pensando os processos de legitimação/distinção referem-se aos modos pelos quais os vários grupos e setores da sociedade campinense tomam para si o discurso da veracidade cultural e da legitimidade identitária, onde deslegitimar o outro corrobora a própria legitimação.

Em um lugar monopolizado por bebidas e comidas a diferenciação ocorre pelo fator econômico apoiada na ressemantização. Pagar mais caro pela mesma bebida que todos bebem parece desarrazoado. Mas seu sentido lógico apóia-se na diferenciação entre aqueles que podem pagar até cinquenta por cento mais caro possuindo o sentimento e a tranquilidade de que "não é pra qualquer um" estar ali, até por que "não é pra quem quer, é pra quem pode" frase tipicamente ouvida. Olhar para os lados e encontrar gente parecida com você é o reconforto da distinção, da estratificação social. Não estarão ali os "maloqueiros" da parte superior nem os bêbados que dançam debaixo das caixas de som espalhadas pela festa. As "piriguetes" e mulheres vulgares da Pirâmide, o famigerado "forró da facada", com seus senhores desdentados, com os jovens que carregam debaixo do braço as "batidas" coloridas feitas em casa para economizar dinheiro, que vem e voltam caminhando da festa em grupos, certamente não estarão nas barracas. 


\section{TIAGO FERNANDES ALVES}

A estratificação garante a paz das classes abastadas, daqueles que querem se separar dos bandos do povo, de sua mistura perigosa pela violência dos assaltos e da "gente feia" que enche a pista de dança do "forró da facada". Paga-se mais caro para não se misturar com o todo, pertencer somente a um pequeno Feudo destinado aos escolhidos e pela meritocracia. $\mathrm{O}$ sucesso lhe garante a possibilidade de pagar mais caro por uma mesma mercadoria, mas que não é a mesma, não pode ser a mesma, diferenciada por seus vários nomes e significados.

O pejorativo nome dado à Pirâmide e seus entornos, "forró da facada", é utilizado como criminalização do lugar, apropriado para pessoas de má índole e com más intenções. Porém, esse mesmo lugar é apropriado pelo setor empresarial - uma rede televisiva que possui uma filial na cidade - nos sábados pela manhã. Seu espaço é cercado, sendo sua entrada permitida apenas a convidados. Este espaço/tempo é chamado de "Momento Junino". Percebe-se que, ao tomar posse do espaço da Pirâmide, a classe abastada, a mesma que frequenta a parte inferior, significa o lugar como o "verdadeiro" momento da festa de São João. Espaço destinado aos empresários e políticos que participam da elaboração da festa, os agentes responsáveis por sua realização. Ao cair da noite, quando as cercas são retiradas e a população novamente toma posse do espaço, a Pirâmide se torna o "forró da facada" - certamente este não é o termo utilizado pelos que nela se encontram.

Na Pirâmide pudemos encontrar pessoas em geral mais velhas onde muitas dançam sozinhas ou estão à procura de um parceiro ou parceira de dança. Possui um pequeno palco que comporta atrações de menor porte. Porém, possuía a mais elaborada ornamentação de toda a festa em sua parte interna, com bandeirolas, balões de São João e imagens dos santos festejados.

O mesmo espaço também comporta os desfiles das quadrilhas juninas. Nestes dias de competição o espaço é tomado por curiosos que quase nunca teriam a coragem de sequer passar pela Pirâmide, e pela torcida das quadrilhas que representam bairros e comunidades da cidade. O mesmo espaço é semanticamente ressignificado no mesmo dia várias vezes, tendo seu Momento Junino pela manhã, desfiles de quadrilhas juninas à noite, e logo em seguida as bandas e trios de forró, em geral bandas de menor expressão.

A "cana" também sofre ressignificação ainda que tenha sido a mesma comercializada em toda a festa. Nas barracas não se vai "tomar cana", mas "beber cerveja”. A cachaça pode sofrer outras eufemizações por parte do público das barracas. O termo "aperitivo" permite à cachaça sua valorização. Servida em garrafas resfriadas ganham respeitabilidade, tomada em pequenas doses acompanhada com caldinhos e petiscos variados. Ao contrário da "cana" que se "toma", da "brejeira" de engenhos desconhecidos, fabricada artesanalmente, bebida que se "toma" não como aperitivo, mas como a bebida da noite inteira, mais barata e eficaz, o "aperitivo" representa um momento lúdico, a apreciação/consumo do que é legítimo, tradicional e da terra.

Contudo, as estratégias, as lutas pela distinção semiológica nos modos de consumação das bebidas e comidas, na busca por sua desvalorização por parte das classes abastadas, permitem/propiciam aos demais a tática de valorização daquilo que é mais humilde, daquilo que é do povo, aquele não tem "frescura". As relações de poder assumem, portanto, caráter relacional, perlocutória ${ }^{X X X}$ que se realizam nos atos de fala, nas formas semiológicas significadas e ressignificadas no âmbito das relações entre os agentes em grupos ou relacionados aos lugares por eles ocupados. O poder é, portanto, situacional. Ele não se substancializa, não se confere enquanto massa modelável, mas como uma situação pelos quais assumem papeis os agentes envolvidos de acordo com 


\section{ESTRATIFICAÇÃO, SOCIABILIDADES, TÁTICAS E ESTRATÉGIAS NA PRODUÇÃO DE ESPAÇOS NO "MAIOR SÃO JOÃO DO MUNDO"}

\section{TIAGO FERNANDES ALVES}

os espaços por eles preenchidos/produzidos. É realizado no momento em que os discursos ganham plausibilidade e força. Violência impressa sob a forma da desqualificação entre o "tomar" e o "beber", entre a "cana" e o "aperitivo", entre o "churrasquinho" e o "espeto".

\section{PALAVRAS FINAIS}

Os arranjos e reajustes espaciais efetivados pelos agentes sociais no espaço do Parque do Povo demonstraram a complexidade das dinâmicas formas de sociação em um ambiente que parece harmonioso ou confuso para um olhar desatento.

Os agentes em processos constantes de interação fomentam espacialidades que devem ser percebidas enquanto vínculos que são a todo momento feitos e desfeitos, em complexos movimentos de interações e conflitos. Alguns lugares foram solidificados concernentes às espacialidades fronteiriças pertencentes a certos grupos, como os frequentadores dos espaços de sociabilidade dos grupos LGBT's. Para tanto, os conflitos e disputas territoriais são premissas em um ambiente que chega a comportar cem mil pessoas em uma única noite de festa.

Os espaços de sociabilidade referem-se a dinâmicas espaço-temporais perpassadas por seguidas ressignificações relacionadas aos horários e aos grupos que usufruem destas espacialidades na conformação de suas demandas conteudísticas, reelaborando-se em novas formas de sociação. As espacialidades referem-se, portanto, a construções socialmente elaboradas demandadas por grupos e indivíduos em interação em constantes disputas pela apropriação e ressignificação dos espaços preenchidos. São os deslocamentos espaço-temporais que definem os usos e atribuições simbólicas dos espaços em sua produção.

Desse modo, neste imbricado processo de rearranjos espaciais, os grupos são atravessados por uma multiplicidade de agentes que interferem, ou não, em variadas proporções. Os agentes atravessam as várias espacialidades/lugares das mais variadas maneiras. Podem interagir e participar contundentemente das práticas grupais - usar as mesmas roupas e acessórios, ser fumante ou não, utilizar a mesma linguagem e gírias ou compartilhar o mesmo capital cultural para um mínimo de manutenção das conversações - ou reagir de modo conflituoso e desarmonizador - criticar as práticas e vestimentas de outros agentes pertencentes a outros grupos, ser o único fumante da mesa ou o único que bebe cachaça. Contudo, os agentes podem perpassar as espacialidades e os grupos sem efetivar-se, caminhar no limiar de suas fronteiras, apenas erguendo copos para brindes ou escutando as conversas.

No espaço heterogêneo do Parque do Povo nada impede que um roqueiro dance forró, beba cachaça paulista, coma uma fatia de pizza ou acarajé, compre uma camiseta feita artesanalmente de algodão colorido e saia da festa pilotando uma moto de última geração.

\section{Notas}

I Doutorando em Sociologia pelo Programa de Pós-Graduação em Sociologia - UFPB. E-mail: fernalvestiago@gmail.com

II ANDRADE LIMA, Elizabeth Cristina de. A Fábrica de Sonhos: a invenção da festa junina no espaço urbano. Campina Grande: EDUFCG, 1998.

III ANDRADE LIMA, Elizabeth Cristina de. A Fábrica de Sonhos: a invenção da festa junina no espaço urbano, p. 68. 
Iv LEFEBVRE, Henry. A Produção do Espaço. Trad. Doralice Barros Pereira e Sérgio Martins (do original: La production de l'espace. 4e éd. Paris: Éditions Anthropos, 2000). Primeira versão: início - fev. 2006, grifos do autor.

${ }^{\vee}$ CERTEAU, Michael de. A Invenção do Cotidiano. Petrópolis: Vozes, 2012.

${ }^{\text {VI }}$ BAUMAN, Zygmunt. Cultura: rebelde e ingovernável. In: Vida Líquida. Rio de Janeiro: Zahar, 2009, p.71-89.

VII SIMMEL, Georg. Cuestiones Fundamentales de Sociología. Barcelona, Espanha: Gedisa, 2002.

VIII Idem. Georg Simmel: sociologia. Grandes Cientistas Sociais. Evaristo de Moraes Filho (org.). São Paulo: Ática, 1983.

${ }^{\text {IX }}$ FRÚGOLI JÚNIOR, Heitor. Sociabilidade Urbana. Rio de Janeiro: Zahar, 2007.

${ }^{\mathrm{X}}$ Ibid. p. 18.

${ }^{\mathrm{XI}}$ SIMMEL apud FRÚGOLI JÚNIOR, Ibid., p. 10.

XII BARTH, Fredrik. O guru, O Iniciador e Outras Variações Antropológicas. Rio de Janeiro: Contra Capa 2000.

XIII LAHIRE, Bernard. Esboço de uma teoria do ator plural. In: Homem Plural: os determinantes da ação. Petrópolis: Vozes, 1998, p.15-100.

XIV BOURDIEU, Pierre. A Distinção: crítica social do julgamento. Porto Alegre: Zouk, 2011.

${ }^{\mathrm{xV}}$ LAHIRE, op. cit., p.15-100.

${ }^{\mathrm{XVI}}$ RIBEIRO, Gustavo Lins. Antropologia da Globalização: circulação de pessoas, mercadorias e informações. Texto apresentado como uma conferência no Instituto de Altos Estudios Sociales da Universidad Nacional de General San Martín, Buenos Aires, 16 de maio de 2008. Disponível em: http://www.dan.unb.br/images/doc/Serie435empdf.pdf2011.

XVII WACQUANT, Loic. Corpo e Alma: notas etnográficas de um aprendiz de boxe. Rio de Janeiro. Ed. Relume Dumaré, 2002.

XVIII SPINK, Mary Jane. Práticas Discursivas e Produção de Sentidos no Cotidiano: aproximações teóricas e metodológicas. São Paulo: Cortez, 1999.

${ }^{\mathrm{XIX}}$ SIMMEL, Georg. Cuestiones Fundamentales de Sociología. Barcelona, Espanha: Gedisa, 2002.

${ }^{\mathrm{xx}}$ SIMMEL, apud FRÚGOLI JÚNIOR, Sociabilidade Urbana. Rio de Janeiro: Zahar, 2007.

${ }^{x X I}$ LEFEBVRE, Henri. A Produção do Espaço. Trad. Doralice Barros Pereira e Sérgio Martins (do original: La production de l'espace. 4e éd. Paris: Éditions Anthropos, 2000). Primeira versão: início fev.2006.

XXII Idem, p. 36, grifos do autor.

XXIII LEFEBVRE, op. cit.

xxIV BAKHTIN, Mikhail. A Interação Verbal. In: Marxismo e Filosofia da Linguagem. São Paulo: Hucitec, 1999, p. 112, grifos do autor.

XXV Idem, ibidem.

XXVI BOURDIEU, op. cit.

XXVII Idem, ibidem.

XxvIII ALVES, Tiago Fernandes. Na Batida do Meu Boi: inventividade e criatividade na afirmação identitária dos brincantes de bois bumbas de Campina Grande. Disponível em: http://www.ufcg.edu.br/ ppgcs/wp-content/uploads/2012/09/trabalhos-dissert.pdf. 2011.

XxIX DERRIDA, Jaques. Do Direito à Justiça. In: Força de Lei. São Paulo: Martins Fontes, 2010.

\section{REFERÊNCIAS}

ALVES, Tiago Fernandes. Na Batida do Meu Boi: inventividade e criatividade na afirmação identitária dos brincantes de bois bumbas de Campina Grande. Disponível em: http://www.ufcg.edu.br/ ppgcs/wp-content/uploads/2012/09/trabalhosdissert.pdf. 2011.

ANDRADE LIMA, Elizabeth Cristina de. A Fábrica de Sonhos: a invenção da festa junina no espaço urbano. Campina Grande: EDUFCG, 2008. 
BARTH, Fredrik. O guru, O Iniciador e Outras Variações Antropológicas. Rio de Janeiro: Contra Capa 2000.

BAKHTIN, Mikhail. A Interação Verbal. In: Marxismo e Filosofia da Linguagem. São Paulo: Hucitec, 1999.

BAUMAN, Zygmunt. Cultura: rebelde e ingovernável. In: Vida Líquida. Rio de Janeiro: Zahar, 2009, p.71-89.

BOURDIEU, Pierre. A Distinção: crítica social do julgamento. Porto Alegre: Zouk, 2011.

CERTEAU, Michael de. A Invenção do Cotidiano. Petrópolis: Vozes, 2012.

DERRIDA, Jaques. Do Direito à Justiça. In: Força de Lei. São Paulo: Martins Fontes, 2010.

FRÚGOLI JÚNIOR, Heitor. Sociabilidade Urbana. Rio de Janeiro: Zahar, 2007.

LAHIRE, Bernard. Esboço de uma teoria do ator plural. In: Homem Plural: os determinantes da ação. Petrópolis: Vozes, 1998, p.15-100.

LEFEBVRE, Henri. A Produção do Espaço. Trad. Doralice Barros Pereira e Sérgio Martins (do original: La production de l'espace. 4e éd. Paris: Éditions Anthropos, 2000). Primeira versão: início - fev.2006.

RIBEIRO, Gustavo Lins. Antropologia da Globalização: circulação de pessoas, mercadorias e informações. Texto apresentado como uma conferência no Instituto de Altos Estudios Sociales da Universidad Nacional de General San Martín, Buenos Aires, 16 de maio de 2008. Disponível em: http://www.dan.unb.br/images/doc/Serie435empdf.pdf

SIMMEL, Georg. Cuestiones Fundamentales de Sociología. Barcelona, Espanha: Gedisa, 2002.

SIMMEL, Georg. Georg Simmel: sociologia. Grandes Cientistas Sociais. Evaristo de Moraes Filho (org.). São Paulo: Ática, 1983.

SPINK, Mary Jane. Práticas Discursivas e Produção de Sentidos no Cotidiano: aproximações teóricas e metodológicas. São Paulo: Cortez, 1999.

WACQUANT, Loic. Corpo e Alma: notas etnográficas de um aprendiz de boxe. Rio de Janeiro. Ed. Relume Dumaré, 2002. 